\title{
ZEYLANEMA SAILUENSIS N.SP. (CAMALLANIDAE, CAMALLANINAE ZEYLANEMA YEH,1960) FROM OPHIOCEPHALUS STRIATUS (BLOCH)
}

\section{R. M. KHADAP}

Department of Zoology, Nuthan College Sailu. Dist. Parbhan (M.S.)

\begin{abstract}
The present communication deals with a new species of the genus Camallanus. The new worm Zeylanema sailuensis n.sp is studied from Ophiocephallus striatus (Bloch). It shows remarkable difference from other known species of Zeylanema in respect to body length, disposition of the papillae, tail, length and the length of spicule.
\end{abstract}

Key words : Zeylanema sp., Freshwater fishes, Nematode parasites.

\section{INTRODUCTION}

The worms were collect from the intestine of Ophiocephalus striatus at Sailu, Maharashtra State. After its detailed study they were found to be new forms of the genus Zeylanema having a single spicule. The present work is based on the study of nine male specimens.

\section{MATERIAL AND METHODS}

The male and female nematodes described in this paper collected from the intestine of Ophiocephalus striatus, obtained from the various dams, lakes, river streams etc. The nematode were fixed in hot $70 \%$ alcohol. The worm were later preserved in fresh $70 \%$ alcohol to which $10 \%$ glycerine was added. The specimen were cleared in Lactophenol. The worms were mounted in glycerine. All drawings were made with the aid of camera lucida and all measurements are expressed in millimeters.

\section{Description :}

The worm are whitish yellow in colour, cylindrical in shape and are of uniform thickness throughout length except posterior. The cuticle is smooth, buccal capsule consist of two valves with two external thickening and fourteen beaded longitudinal ridges. The buccal valve excluding the posterior chitinous rings measures $0.048 \mathrm{~mm}$ in length and $0.054 \mathrm{~mm}$ in maximum breadth. The tridents are situated laterally. The nerve ring is situated at $0.10-0.12 \mathrm{~mm}$ from anterior end. The total length of the oesophagus is $0.052-0.059 \mathrm{~mm}$ of which the muscular and glandular portions are $0.21-0.25 \mathrm{~mm}$ and 0.32 $0.36 \mathrm{~mm}$ long (Figs. $1 \& 2$ ).

The length of the body is $3.25-3.45 \mathrm{~mm}$ and has a maximum body diameter of $0.14 \mathrm{~mm}$. The tail is provided with a short narrow caudalalae. The caudal ale are supported by fourteen pairs pedunculated and two sessile papillae. The disposition of the papillae is seven preclocal two adcloacal and seven post cloacal. The papillae are grouped into two each and last two sessile. There is only a single spicule measuring 0.33 $0.38 \mathrm{~mm}$. The gubernaculums is absent. The tail is short and bifurcated at its tip measuring $0.09-0.25 \mathrm{~mm}$.

\section{RESULTS AND DISCUSSION}

The genus Camallus was created by Pearse (1933) who described C.anabantis from Anabas testudineus. In the original description Camallanus anabantis by Pearse (1933). There is a marked discrepancy. He described male specimens as having trident and females, which were smaller devoid of tridents. A comparison for the study made by Pearse (1933) and Yeh (1960) elucidates that pears dealt with two distinct species. One with tridents and without tridents. Yeh (1960) also found a mixed infection of number of species of Camallanidae in single host.

The author agree with Yeh (1960), according to whom certain evolutionary characters must be taken into consideration for assigning a generic status. Yeh (1960) considers that spicule have a little systematic importance since they are often hardly visible because of very weak and light sclerotization and sometimes they are missing. According to him buccal capsule in family Camallanidae has remarkable evolutionary significance due to their heavy sclerotization, consistency and non variability with slow rate of evolution. A fundamental diagnostic feature of a particular genus. Considering points Yeh (1960) the present worm is included under the genus Zeylanema. Yeh (1960) erected the genus Zeylanema on the basis of the presence of ridges or beaded structures in the buccal capsule. According to him all the species of Camallanus with beaded or toothed ridges are place under the genus of Zeylanema. Thus at the present the valid species of Zeylanema are as under Z.sweeti (Moorthy,1937 and Yeh,1960). Zeylanema unispiculus (Khera,1954 and Yeh, 1960). Z.pearsi (Yeh,1960). Z.kulasiririi (Yeh, 1960), Z.bahi (Sahay and Sinha,1965). Z.mastacembeli (Sahay and Sinha, 1965). Z.spinosa (Furtado,1965). Z.magna (Khan and Yaseen,1969). Z.ophiocephali (Shendge and Deshmukh, 1977).

The present worm is closest to Z.ophiocephali in having adcloacal papillae as size of spicule. It's also closest to Z.mastacembeli in having adclocal papillae. But it differs from the other species. In view of the difference cited above the author regards form as new and named as Zeylanema sailuensis n.sp. 


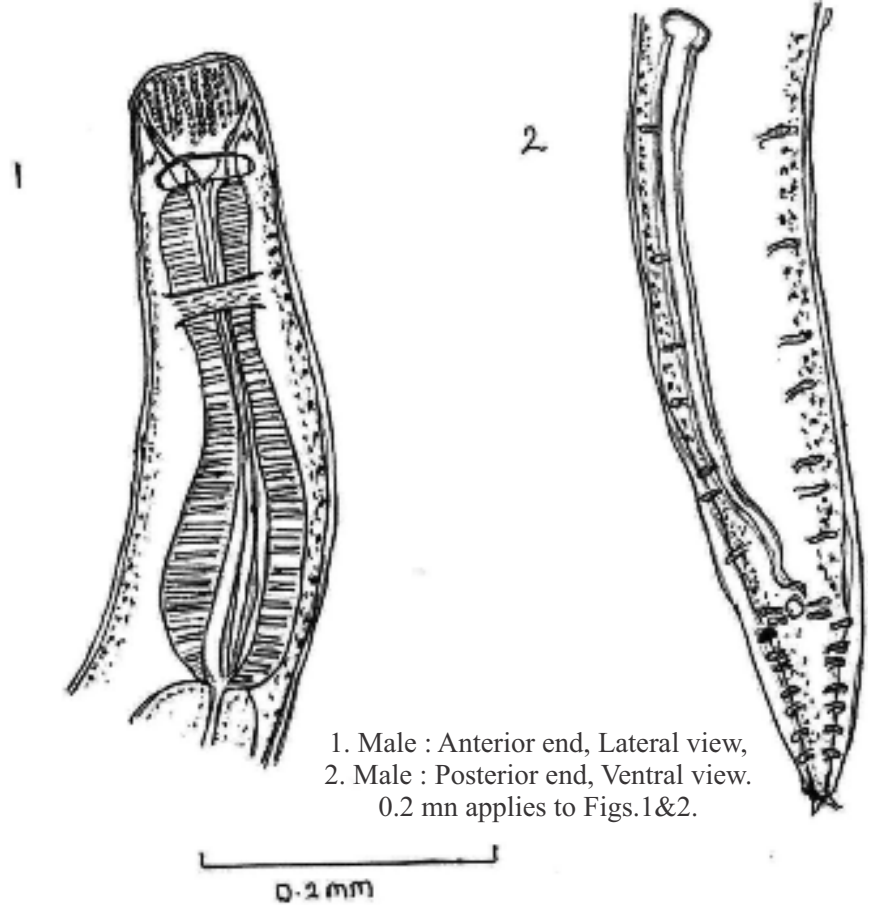

Figs. 1\&2 Zeylanema sailuensis sp.

Host $\quad$ Ophicephalus striatus
Habitat $\quad:$ Intestine
Locality $\quad$ Sailu, Maharashtra, India.

\section{ACKNOWLEDGMENT}

The authors are thankful to the Principal, Nutan Mahavidyalaya Sailu, for providing laboratory facilities.

\section{REFERENCES}

Alli, S. M. (1956). Studies on the nematode parasites of fishes and bird found in Hyderabad. Indian J. Helminth., 8 : 1- 83.

Ali, N. M.; Salih, N. E. and Abdul Ameer, K. N. (1987). Parasitic fauna of some freshwater fishes from Tigris river, Baghdad, Iraq. Iv Nematode. J. Biological Sci. Res., 18(3) : 35-45.

Arya, S. N. (1978). Nematode fauna of Kumaon region 1. Three new Camallanids from fresh water fishes of Nainital. Indian J. Helminthol., 30(2) :110-121.

Agrawal, V. (1965). Some new nematode parasites from fresh water fishes of Lucknow. Indian J. Helmith., 17 : 1-17.

Khera S. (1954). Nematode parasites of some vertebrates. Indian J. Helmith., $6: 27-133$.

Kuasiri, C. and Fernando, C. H. (1956). Camallanidae parasitic in some Ceylonese fish. Parasitology, 46 : 420-424.

Moorthy, V. N. (1937). Camallamus sweeti n.sp. a new species of Camallanidae, Nematode. J. Parasit., 23 : $302-306$.

Pearse, A. S. (1933). Parasites of Siamese fishes and crustaceans J. Siam. Soc. Nat. Hist. Supp., 9: 179-191.

Sahay, U. and Sinha (1966). On the Zeylanema mastacembeli n.sp. (Camallanidae. Camallanine, Zeylanema Yeh,1960) from Mastacembelus armatus (Lacep) Japan. J. Med. Sci. Biol., 19: 247-252.

Shendge, S. R. and Deshmukh, P. G. (1977). On Zeylanema ophiocephali n.sp. (Camallanidae, Camallaninae, Zeylanema Yeh, 1960) from Ophiocephalus striatus (Bloch). Rivista di Parasitologia, XXXVIII : N2/3.

Yamaguti, S. (1961). Systema helminthum : Vol. III Part I\&II. Nematodes of Vertebrates Inter Science Publishers Inc., New York, pp. 1-1261.

Yeh (1960). On a collection of Camallanid nematode from freshwater fish in Ceylon. J. Helminth, 34(1/2) : 107-116.

Yeh (1960). On the reconstruction of the genus Camallanus Raillet and Henry,1915. J. Helminth, 34 : 117-124.

Yorke, W. and Maplestone, P. A. (1926). The nematode parasites of Vertebrates. J. and A. Churchill, London. 